\title{
Effect of Hot-stamping on the Properties Change of Compound Layer in Coated High-strength Steel Plate
}

\author{
Dong-Gyu Kim ${ }^{1}$, Jong-Hoi Woo ${ }^{1}$, Kyoung-Hee Gu ${ }^{1}$, Young-Min Son ${ }^{1}$, In-Duck Park ${ }^{2}$, Ki-Woo Nam 1,* \\ 1 Pukyong National University, 45 Yongso-ro Nam-gu, Busan, 48513, Korea; dgkim@pknu.ac.kr (D.G.K.), \\ doolnam@posco.com (J.H.W.), rnrudgm16455@naver.com (K.H.G.), sym931119@naver.com (Y.M.S.), \\ parkid@kimm.re.kr (I.D.P.), namke@pknu.ac.kr (K.W.N.) \\ 2 Korea Institute of Machinery \& Materials, 156 Gajeongbuk-ro Yuseong-gu Daejeon, 34103, Korea; e-mail@e- \\ mail.com \\ * Correspondence: namkw@pknu.ac.kr; Tel.: +82-51-629-6358
}

\begin{abstract}
In this study, the effect of hot stamping forming process on the properties change of compound layer in Al-Si coated high-strength steel sheet with different thickness was investigated. The coating layer in hot stamped high-strength steel sheet was composed of a diffusion layer and a compound layer. As the hot stamping temperature and holding time for forming increased, the thickness of the compound layer in the Al-Si coated high-strength steel sheet increased. The thickness of coating layer with the hot stamping for $500 \mathrm{sec}$ at 890,910 and $950{ }^{\circ} \mathrm{C}$ was obtained 8.9, 11.8, and $20.6 \odot \mathrm{m}$, respectively. The thickness of coating layer with hot stamping for 180, 500 and $550 \mathrm{sec}$ at $910{ }^{\circ} \mathrm{C}$ was obtained 5.7, 11.8, and $17.8 \odot \mathrm{m}$, respectively. The compound layer in hot stamped highstrength steel sheet with $\mathrm{Al}-\mathrm{Si}$ coating layer consists of $\mathrm{Al}_{5.4} \mathrm{Fe}_{2}$ and $\mathrm{Fe}_{2} \mathrm{Si}$ phases. In the compound layer, $\mathrm{Al}$ and $\mathrm{Si}$ were irregularly distributed.
\end{abstract}

Keywords: hot stamping; coating layer; diffusion layer; high-strength steel sheet; heating time; heating temperature

\section{Introduction}

Recently, transportation equipment related industries are trying to solve problems such as the regulation of fossil fuel use as an environmental problem, and resource saving due to fuel exhaustion. [1,2] The most efficient method to solve this problem is to improve fuel efficiency by lowering the weight of transportation equipment.

To date, strategies to improve fuel efficiency in the transportation equipment industry are to improve the efficiency of transportation equipment components, reduce rolling resistance, and lower the weight of transportation equipment. [3,4] Improvement in component efficiency and fuel efficiency by the reduction of rolling resistance have reached their limit. [5] Therefore, the lowering the weight of transportation equipment is the most efficient method to improve fuel efficiency.

Currently, various methods are being used to attempt to reduce the weight of transportation equipment. That is, materials for transportation equipment components are replaced by materials with higher strength and toughness than conventional materials, or ferrous alloys with high specific gravity are replaced by non-ferrous alloys with high specific strength. These studies are being actively conducted. Kim et al [6] investigated to effect of $\mathrm{Zr}$ addition on phase transformation and precipitation in B-added hot stamping steels. Windmann et al [7] investigated phase formation as a function of coating thickness and $\mathrm{Si}$ content at the steel substrate/coating interface. They investigated mechanical property and microstructural characterization. [8,9] Gui et al [10] obtained that the Al-Si coating gave an unignorable influence on the thermo-mechanical properties of the boron steels. Suh et al [11] show that volume changes isotropically during phase transformations. However, if the desired conversion is to a high-strength material or a material 
having a high specific strength, material development having such properties is also important. However, various optimal manufacturing process technologies must be developed according to manufacturing the components of transportation equipment using the developed materials. In addition, to improve the product reliability and achieve the reduction of cost in manufacturing the components, development of this optimal manufacturing process technology is urgently required.

Since as the strength of steel sheet increases, elongation decreases, it is difficult for the hot stamping method to mold components. Lee at el [12] evaluated the surface alloying of 55 wt.\% Al-Zn coated press hardening steel during a press hardening heat treatment. The increasing of heating rate during the austenitization cycle showed in a high volume fraction of $\mathrm{Zn}$ at FeAl grain boundaries, and the presence of $\mathrm{Zn}$ islands in $\mathrm{Fe}_{2} \mathrm{Al}_{5}$ grains. Alléy et al [13] compared the corrosion resistance of aluminized press hardened steel Usibor ${ }^{\circledR}$ AlSi and untreated 22MnB5 steel. Dosdat et al [14] evaluated the corrosion resistance using aluminized, galvanized or galvannealed boron steels. Therefore, the hot stamping method overcomes this problem, and prevents cracks occurring during the forming of coated high-strength steel sheet, thereby ensuring high-strength and formability at the same time. Lee et al [15] evaluated the thermo-mechanical behavior of hot press formed sheet by finite element analysis, which considers transformation induced plasticity during phase transformations. Hayashi et al [16] examined the decarburization behavior in the hot stamping using a Fe-0.21 wt.\% C-1.3 wt.\% Mn-0.2 wt.\% Si steel. Hamamoto et al [17] developed the steel sheet in order to overcome low press productivity and limitation in the shapes of parts by hot stamping. However, there are few studies on the thickness of the diffusion layer of the coating depending on the temperature and time of hot stamping. Therefore, it is necessary to examine the influence of temperature and time on the thickness of the diffusion layer.

Therefore, this study was carried out to obtain basic data for the development of the optimal process required for manufacturing components by the hot stamping method. That is, the coated SABC 1470 steel sheet was heated at different temperatures and times. Then, after the press hardenable steel (PHS) products were manufactured by the hot stamping method, the thickness and microstructural change of the coating layer (compound layer and diffusion layer) according to the change of the heating temperature and the holding time were investigated.

\section{Samples and experimental methods}

\subsection{Sample and hot-stamping molding}

The sample used in the study was used by coating the SABC 1470 steel sheet of thickness $1 \mathrm{~mm}$ with a coating solution of $40 \%$ Al-10\% Si-Fe. Table 1 show chemical compositions (wt.\%) and mechanical properties of the SABC1470 steel used in the hot stamping test. Since it is for observation of the coating layer, one each was used. The hot stamping was performed at heating temperatures of 890,910 , and $950{ }^{\circ} \mathrm{C}$ with the coated steel sheet, and the holding time at each temperature was 180, 500, and $850 \mathrm{sec}$. Figure 1 shows schematic of hot stamping process.

Table 1 Chemical compositions (wt.\%) and mechanical properties of the SABC1470 steel used in the hot stamping test.

\begin{tabular}{c|c|c|c|c|c|c}
\hline $\mathrm{C}$ & $\mathrm{Si}$ & $\mathrm{Mn}$ & $\mathrm{P}$ & $\mathrm{S}$ & $\mathrm{B}$ & $\mathrm{Fe}$ \\
\hline \hline 0.21 & 0.26 & 1.27 & 0.017 & 0.003 & 0.0028 & Bal. \\
\hline \multicolumn{2}{c|}{ Yield strength $(\mathrm{MPa})$} & \multicolumn{2}{c}{ Tensile strength (MPa) } & \multicolumn{3}{c}{ Elongation (\%) } \\
\hline \multicolumn{2}{c|}{509} & \multicolumn{2}{|c|}{672} & \multicolumn{3}{c}{18} \\
\hline
\end{tabular}




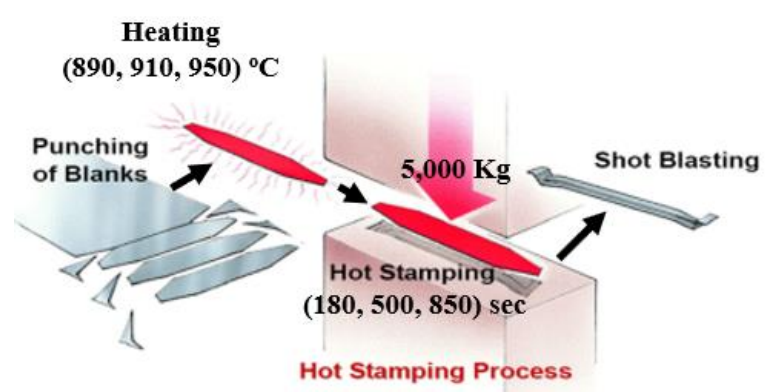

Figure 1. Schematic of hot stamping process

\subsection{Microstructure observation}

The microstructure changes of the base metal and the coating layer according to the heating temperature and the holding time for hot stamping were observed by optical microscopy (Olympus; AX70-32HO2, Japan) and scanning electron microscopy (SEM, Tescan(Vega II LSU), Czech).

\subsection{Thickness measurement of coating layer}

The thickness change of the coating layer according to the changes of heating temperature and holding time was measured by hardness test and line profile analysis of Electron Probe Micro Analyzer (EPMA, S-2400, JEOL, Japan). The thickness was measured 5 times, and averaged. In addition, the analysis of EPMA was measured by examining the concentration change of $\mathrm{Al}, \mathrm{Si}, \mathrm{C}$, and Fe by line analysis inside the sample surface.

\subsection{Microstructure observation of the coating layer (alloy layer)}

The phases in the coating layer of the hot stamping sample were observed using Xray diffraction and transmission electron microscopy (TEM). X-ray diffraction (Rigaku, D/Max-IIA, Japan) was analyzed at $0.04^{\circ}$ intervals in the Bragg angle range $2 \theta=(20-100)^{\circ}$ using Mo-K $\alpha$ characteristic X-ray. The compound analysis was conducted using the peak corresponding to each phase from the diffraction curve. TEM (Hitach, H-7500, Japan) observation was carried out by polishing the hot stamped sample, and making a thin film by jet polishing.

\section{Experimental results and discussion}

\subsection{Microstructure observation}

Figure 2 shows the microstructure of SABC 1470 steel sheet coated for hot stamping observed by optical microscopy, in which $\mathrm{A}$ is the coating layer (compound layer and diffusion layer), and B is a SABC 1470 steel sheet.

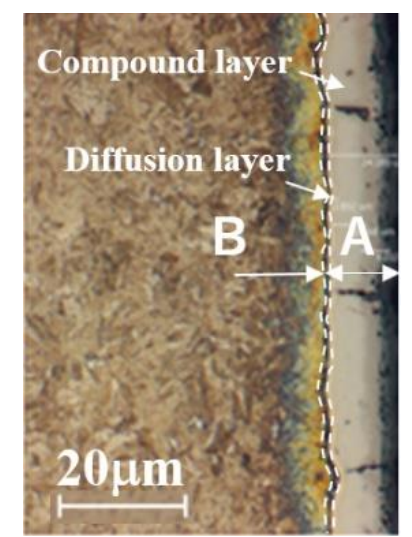

Figure 2. Optical micrograph of the SABC 1470 steel sheet with coating layer. 


\subsection{Effect of hot-stamping on the microstructure of the coating layer}

Figure 3 shows the microstructure of the sample subjected to hot stamping after heating the coated SABC 1470 steel sheet at $910{ }^{\circ} \mathrm{C}$ for $500 \mathrm{sec}$. The microstructure is composed of (a) a compound layer, (b) a diffusion layer, and (c) a SABC 1470 steel sheet having martensite structure. The thickness of diffusion layer is 11.8 ๑m. From this result, it can be seen that when the coated steel sheet is hot stamped, the coating layer is composed of a compound layer and a diffusion layer. In addition, the compound layer as well as the diffusion layer must be strictly managed, because it acts as a cause of crack in the hot stamping process.

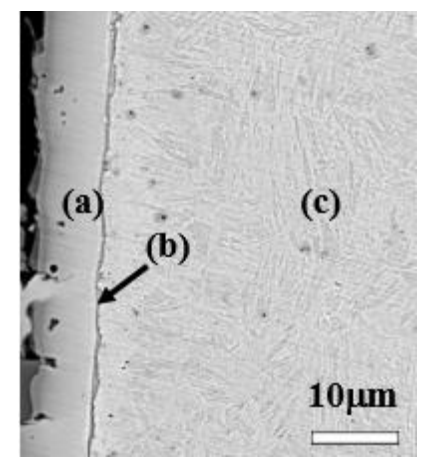

Figure 3. SEM micrographs of the hot stamped steel sheet at $890^{\circ} \mathrm{C}$ for $500 \mathrm{sec}$.

Figure 4 shows the distribution of main elements in the compound layer and the diffusion layer by EPMA after the coated SABC 1470 steel sheet had been hot stamped. The sample was hot stamped after heating at $890{ }^{\circ} \mathrm{C}$ for $500 \mathrm{sec}$. Line profile was performed from the surface to the inner side. In the compound layer of a), $\mathrm{Al}$ and $\mathrm{Si}$ are irregularly distributed, and a very thin diffusion layer was formed, while (b) shows the enlarged vertical axis of (a). This was expanded to understand in detail the distribution of major elements in the compound layer and the diffusion layer. The diffusion layer shows that $\mathrm{Si}$, which was present in the coating layer before hot stamping, hardly diffuses, and the diffusion layer is mainly made by the diffusion of $\mathrm{Al}$. This is because $\mathrm{Al}$ has a lower melting point than $\mathrm{Si}$, and at the same temperature is more thermally activated.

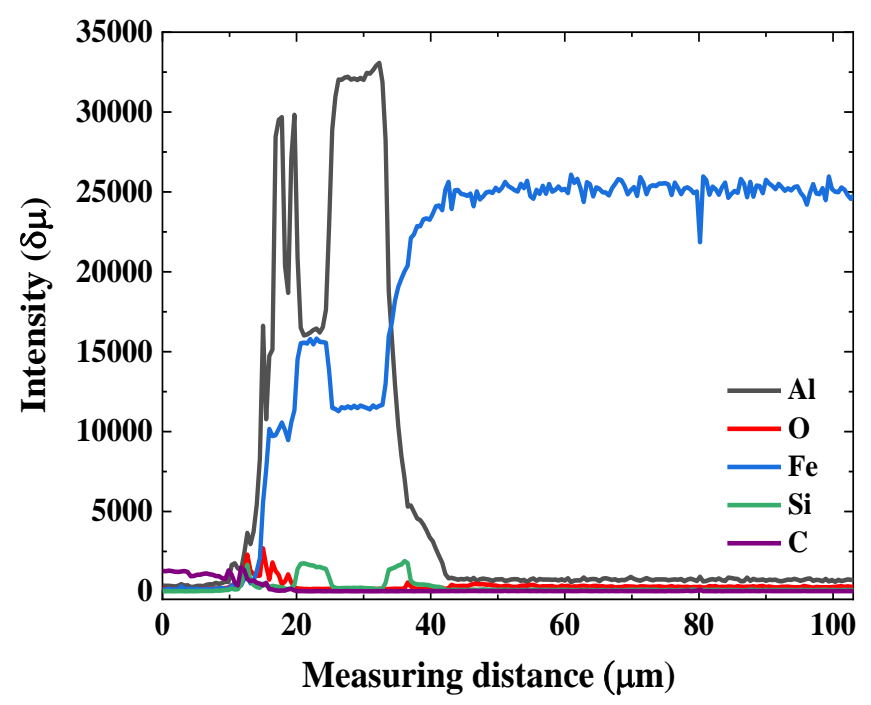

(a) 


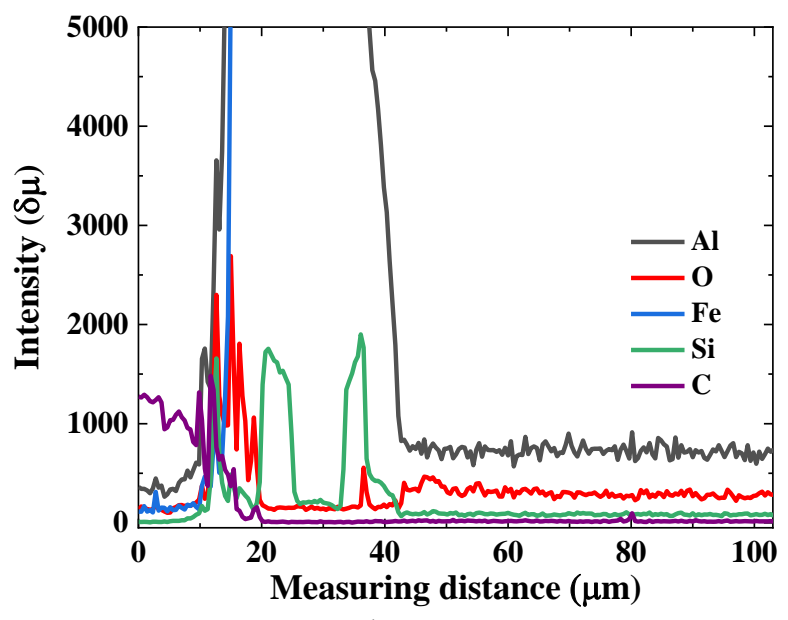

(b)

Figure 4. (a) EPMA line profile of the hot stamped sample, (b) enlarged vertical axis of (a)

Figure 5 shows the coating layer thickness according to the hot stamping temperature. The coated SABC 1470 steel sheet was heated for $500 \mathrm{sec}$ at different temperatures. All samples confirmed the formation of the compound layer and the diffusion layer, regardless of the hot stamping temperature. In addition, it can be seen that as the temperature increases, the thicknesses of the compound layer and the diffusion layer increase. The reason is that as the temperature increases, $\mathrm{Al}$, which was present in the coating layer before hot stamping, diffuses more rapidly into the base metal. The thickness of coating layer with hot stamping for $500 \mathrm{sec}$ at 890,910 and $950{ }^{\circ} \mathrm{C}$ was obtained 8.9, 11.8, and $20.6 \odot \mathrm{m}$, respectively. The hot stamping temperature of $890^{\circ} \mathrm{C}$ is a martensite structure with a small amount of pearlite and a ferrite structure. On the other hand, it can be seen that both the hot stamping temperatures of 910 and $950{ }^{\circ} \mathrm{C}$ have martensite structure. In addition, it is evident that the size of the martensitic lath is slightly larger in the case of $950^{\circ} \mathrm{C}$ than at $910^{\circ} \mathrm{C}$. The temperature at $890^{\circ} \mathrm{C}$ is higher than the $\mathrm{A} 3$ $\left(766{ }^{\circ} \mathrm{C}\right)$ transformation point of $\mathrm{SABC} 1470$ steel, so during heating, it has a single-phase austenite structure. However, the transfer to mold after heating and the mold temperature decreasing during hot stamping made small amounts of pearlite and ferrite structures. Therefore, during forming and cooling, only the austenite structure is transformed into martensite structure, and thus pearlite and ferrite are made at the martensite structure. On the other hand, 910 and $950{ }^{\circ} \mathrm{C}$ are single-phase austenite structures when forming, even if the temperature decreases during the transfer process for hot stamping after heating. Austenite was transformed into martensitic structure during both hot stamping and cooling. In addition, it well known that the martensitic lath size increases slightly, since as the temperature increases, the supercooling increases.

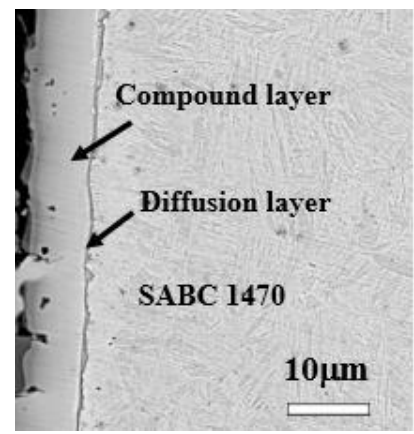

(a)

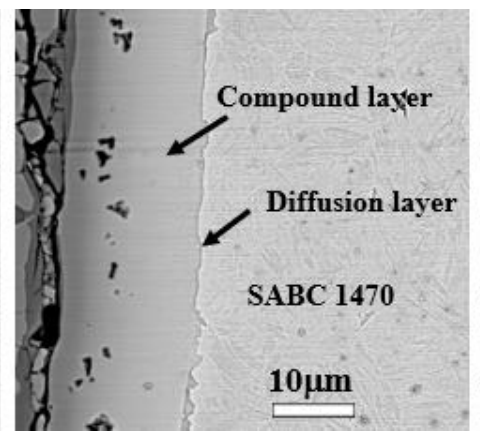

(b)

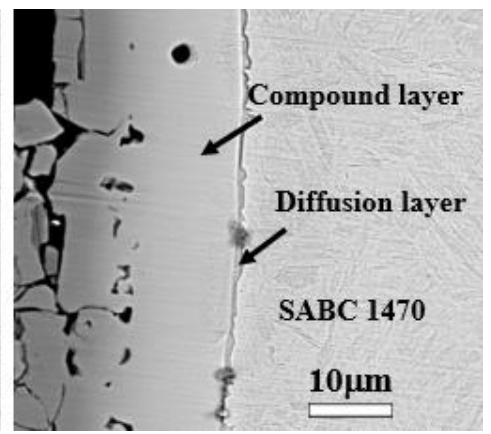

(c)

Figure 5. Coating layer according to different hot stamping temperature at heating time of $500 \mathrm{sec}$ at (a) 890 , (b) 910 , and (c) $950{ }^{\circ} \mathrm{C}$.

Figure 6 shows the observation of the coating layer with different heating time at a hot stamping temperature of $910{ }^{\circ} \mathrm{C}$. All samples confirm the compound layer and the 
diffusion layer, regardless of the hot stamping time. As the heating time increases, the thickness of the coating layer becomes increases. This is because the longer the heating time, the more $\mathrm{Al}$ and $\mathrm{Si}$ in the coating layer before hot stamping diffuse into the base metal. The thickness of coating layer with hot stamping for 180, 500 and $850 \mathrm{sec}$ at $910{ }^{\circ} \mathrm{C}$ was obtained 5.7, 11.8, and $17.8 \odot \mathrm{m}$, respectively. Regardless of the heating time, all three samples have martensitic structure, and as time increases, the martensitic lath size slightly increases. [18-20] It was found that the hot stamped samples consist of a compound layer, a diffusion layer, and a base metal; and as the heating temperature and heating time increase, the thicknesses of the compound layer and the diffusion layer increase.

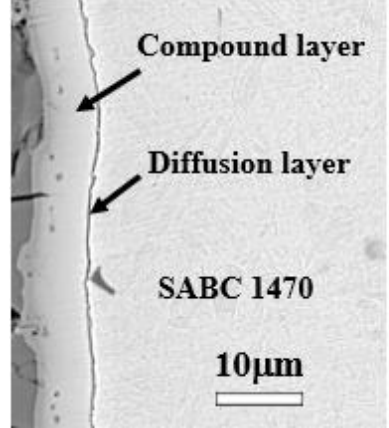

(a)

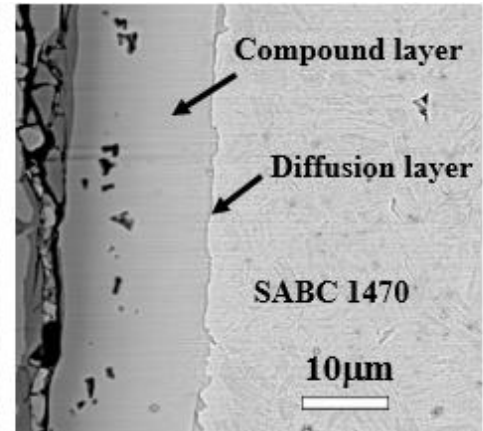

(b)

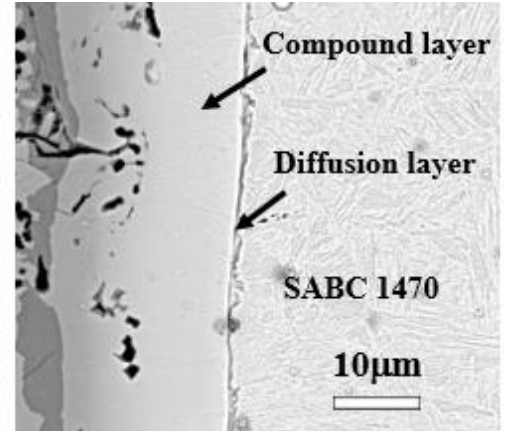

(c)

Figure 6. Coating layer according to different heating time at hot stamping temperature of $910{ }^{\circ} \mathrm{C}$ at (a) 180, (b) 500, and (c) $850 \mathrm{sec}$.

\subsection{Compound of coating layer}

In the SABC 1470 steel sheet coated with $40 \% \mathrm{Al}-10 \%$ Si-Fe solution, a compound layer and a diffusion layer were formed in the coating layer before formation by reaction and diffusion of $\mathrm{Al}$ and $\mathrm{Si}$ in the coating layer during the heating process for hot stamping. It was found that the concentration of the main elements of the coating layer was irregularly distributed. Therefore, the components of the coating layer composed of the compound layer and the diffusion layer were investigated.

Figure 7 shows an analysis of the elements of a hot stamped sample after heating at $910{ }^{\circ} \mathrm{C}$ for 500 sec. A bright-field image (BF) using TEM shows the coating layer (compound layer and diffusion layer), and the distribution of main elements was mapped by EDS (Energy Dispersive X-Ray Spectroscopy). In addition to $\mathrm{Fe}, \mathrm{Al}, \mathrm{Si}$, and $\mathrm{C}$ can be identified in the compound layer and diffusion layer of the bright-field image.

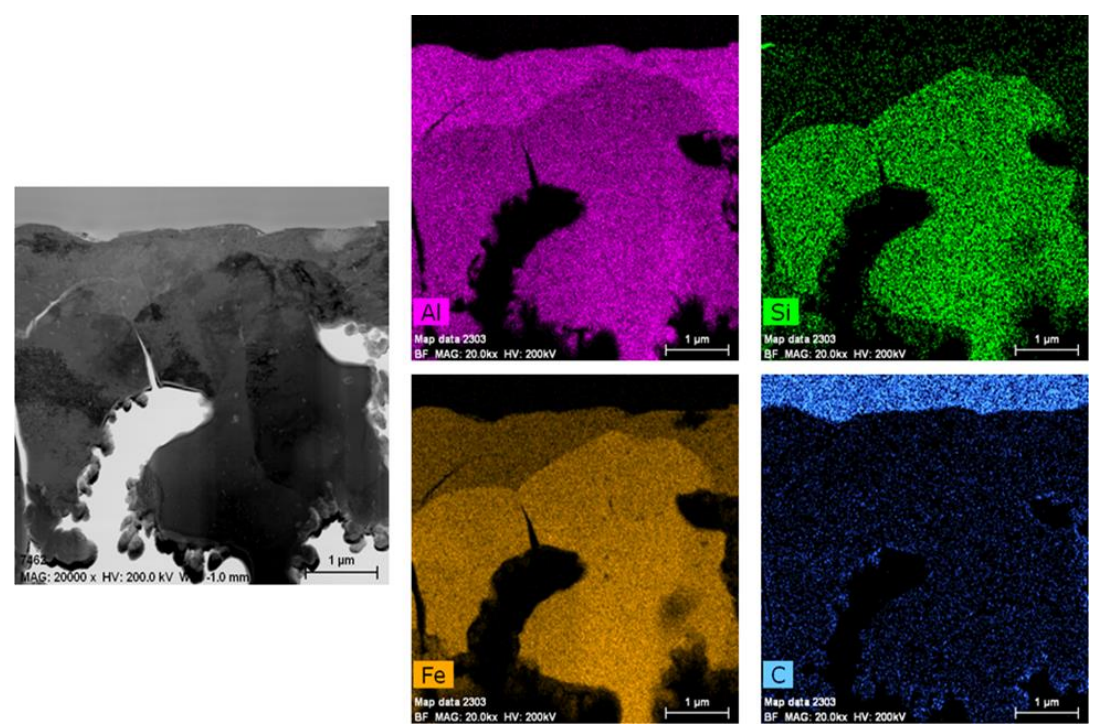

Figure 7. Bright-field image (left), and elemental mapping (right) of the coating layer in hot stamped steel sheet. 
Figure 8 shows the TEM imagery to analyze the phase of the coating layer (compound layer and diffusion layer) of the hot stamped steel sheet, in which a) shows the coating layer (plating layer) in a bright-field image, while b) shows the Selected area electron diffraction patterns (SADP) of the compound (point 1 of (a)) present in the brightfield image and its analysis. From this observation, the $\mathrm{Al}_{5.4 \mathrm{Fe}} \mathrm{Fompound}$ was confirmed.

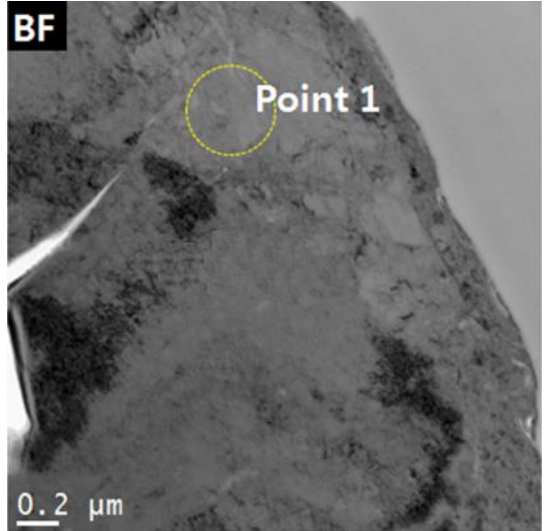

(a)

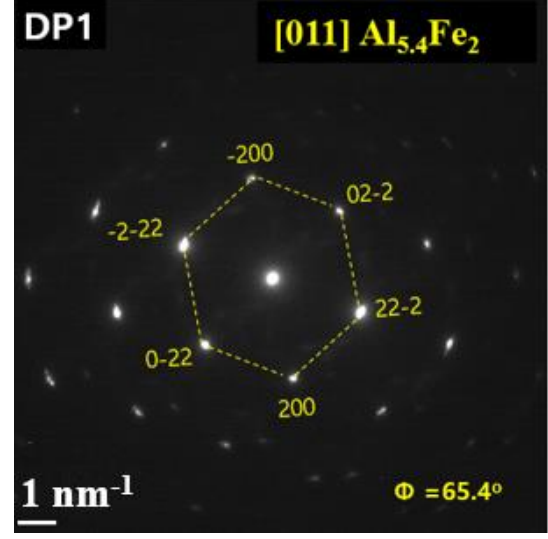

(b)

Figure 8. TEM micrographs of coating layer in hot stamped steel sheet. (a) Bright-field image, and (b) SADP and indexing of SADP.

Figure 9 shows the diffraction curve and analysis obtained by X-ray diffraction of the coating layer of the hot stamped steel sheet after heating at $910{ }^{\circ} \mathrm{C}$ for $500 \mathrm{sec}$. This was investigated by another method for the coating layer compound of the hot stamped steel sheet. In the coating layer, a compound having the structure of $\mathrm{Al}_{5.4} \mathrm{Fe}$ and $\mathrm{Fe}_{2} \mathrm{Si}$ (the composition of the plating solution) was present. Therefore, $\mathrm{Al}$, which was present in the coating layer before hot stamping, was obtained as a compound of $\mathrm{Al}_{5.4 \mathrm{Fe}}$ structure, and $\mathrm{Si}$ was obtained as a compound of $\mathrm{Fe}_{2} \mathrm{Si}$ structure. In general, when a steel sheet coated with a plating solution containing $\mathrm{Al}$ and $\mathrm{Si}$ is heat-treated at a high temperature of 850 ${ }^{\circ} \mathrm{C}$ or higher, compounds such as $\mathrm{FeAl}, \mathrm{Fe}_{3} \mathrm{Al}$, and $\mathrm{Fe}_{2} \mathrm{Al}_{5}$ are obtained. [18-20] However, the hot stamping of this study obtained compounds of $\mathrm{Al}_{5.4 \mathrm{Fe}}$ structure and $\mathrm{Fe}_{2} \mathrm{Si}$ structure.

The above results show that when the SABC 1470 steel sheet coated with $40 \%$ Al-10 $\% \mathrm{Si}-\mathrm{Fe}$ solution is hot stamped, the compound layer can obtain a compound of $\mathrm{Al}_{5.4 \mathrm{Fe}}$ and $\mathrm{Fe}_{2} \mathrm{Si}$.

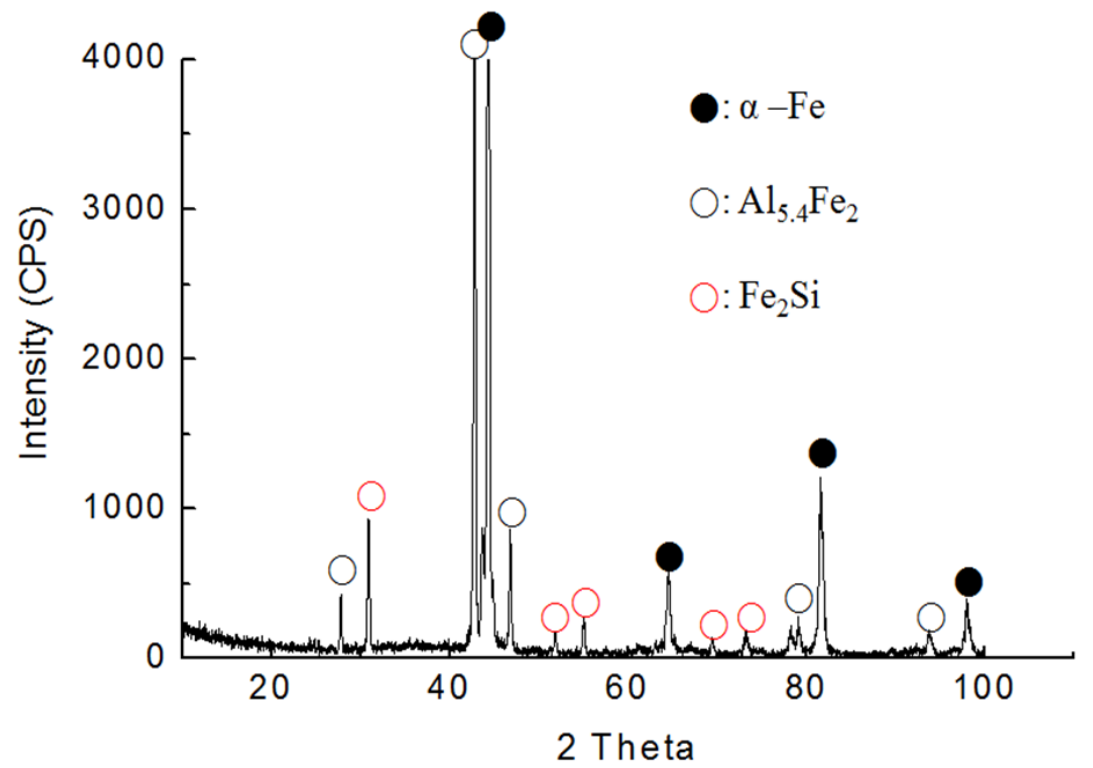


Figure 9. X-Ray diffraction patterns of coating layer after hot stamping.

\section{Conclusions}

In this study, the SABC 1470 steel sheet coated with $40 \% \mathrm{Al}-10 \% \mathrm{Si}-\mathrm{Fe}$ coating solution was hot stamped by change according to the temperature and time, and the coating layer was investigated. The conclusions obtained are as follows:

1) As the heating temperature and the heating time increased, the thickness of the coating layer increased. However, the compound layer, which is the coating layer before forming, did not change.

2) The thickness of coating layer with the hot stamping for $500 \mathrm{sec}$ at 890,910 and $950{ }^{\circ} \mathrm{C}$ was obtained 8.9, 11.8, and $20.6 \mu \mathrm{m}$, respectively.

3) The thickness of coating layer with hot stamping for 180,500 and $550 \mathrm{sec}$ at $910{ }^{\circ} \mathrm{C}$ was obtained $5.7,11.8$, and $17.8 \mu \mathrm{m}$, respectively.

4) The diffusion layer was obtained by diffusion of $\mathrm{Al}$ in the coating layer.

5) The coating layer composed of the compound layer and the diffusion layer obtained a compound of $\mathrm{Al}_{5.4} \mathrm{Fe}$ and $\mathrm{Fe}_{2} \mathrm{Si}$ structures.

Author Contributions: Conceptualization, D.G.K. and K.W.N.; methodology, J.H.W.; investigation, M.H.K. and Y.M.S.; resources, I.D.P.; writing - original draft preparation, K.W.N.; writing - review and editing, K.W.N.; funding acquisition, D.G.K. All authors have read and agreed to the published version of the manuscript.

Funding: This work was supported by a Research Grant of Pukyong National University (2019).

Conflicts of Interest: The authors declare no conflict of interest.

This paper was presented at The 16th Asia-Pacific Conference on Fracture and Strength 2020 (APCFS2020).

\section{References}

1. Perera. F. S. Pollution from Fossil-Fuel Combustion is the Leading Environmental Threat to Global Pediatric Health and Equity: Solutions Exist. Int. J. Environ. Res. Public. Health 2018, 15, 16. https://doi.org/10.3390/ijerph15010016

2. Brauser, S.; Pepke, L.A.; Weber, G.; Rethmeier, M. Deformation behaviour of spot-welded high strength steels for automotive applications. Mater. Sci. Eng. A 2010, 527, 7099-7108. https://doi.org/10.1016/j.msea.2010.07.091

3. Wood, G.M. Lightweight Materials for Transportation. $\quad$ Materials $\quad$ Technology $1993, \quad 8, \quad 221-223$. https://doi.org/10.1080/10667857.1993.11784987

4. Fremgen, C.; Mkrtchyan, L.; Huber, U.; Maier, M. Modeling and testing of energy absorbing lightweight materials and structures for automotive applications. Journal Science and Technology of Advanced Materials 2005, 883-888. https://doi.org/10.1016/j.stam.2005.07.007

5. Z.; LaClair T.; Ou S.; Huff S. Evaluation of electric vehicle component performance over eco-driving cycles. Energy, 2019, 172, 823-839. https://doi.org/10.1016/j.energy.2019.02.017

6. Kim, M.J.; Cho, H.H.; Kim, S.H.; Nam, S.M.; Lee, S.H.; Moon, M.B.; Han, H.N. Effect of Zr addition on phase transformation and precipitation in B-added hot stamping steel. Met. Mater. Int. 2013, 19, 629-635. https://doi.org/10.1007/s12540-013-4001-y

7. Windmann, M.; Rottger, A; Theisen, W. Formation of intermetallic phase in Al-coated hot stamped 22MnB5 sheets in terms of coating thickness and Si content. Surf. Coat. Technol. 2014, 246, 17-25. https://doi.org/10.1016/j.surfcoat.2014.02.056

8. Gorrino, A.; Angulo, C.; Muro, M.; Izaga, J. Investigation of thermal and mechanical properties of quenchable high-strength steels in hot stamping. Metall. Mater. Trans. B 2016, 47, 1527-1531. https://doi.org/10.1007/s11663-016-0662-5

9. Shen, Y.; Hansen, S.S. Effect of the Ti/N ratio on the hardenability and mechanical properties of a quenched-and-tempered C-Mn-B steel. Metall. Mater. Trans. A 1997, 28, 2027-2035. https://doi.org/10.1007/s11661-997-0159-6

10. Gui, Z.X.; Liang, W.K.; Liu, Y.; Zhang, Y.S. Thermo-mechanical behavior of the Al-Si alloy coated hot stamping boron steel. Mater. Design 2014, 60, 26-33. https://doi.org/10.1016/j.matdes.2014.03.011

11. Suh, D.W.; Oh, C.S.; Han, H.N.; Kim, S.J. Dilatometric analysis of austenite decomposition considering the effect of non-isotropic volume change. Acta Mater. 2007, 55, 2659-2669. https://doi.org/10.1016/j.actamat.2006.12.007

12. Lee, C.W.; Choi, W.S.; Cho, Y.R.; De Cooman, B.C. Microstructure evolution of a 55 wt.\% Al-Zn coating on press hardening steel during rapid heating. Surf. Coat. Technol. 2015, 281, 35-43. https://doi.org/10.1016/j.surfcoat.2015.09.041

13. Alléy, C. ; Dosdat, L.; Clauzeau, O.; Ogle, K.; Volovitch, P. Anticorrosion mechanisms of aluminized steel for hot stamping. Surf. Coat. Technol. 2014, 238, 188-196. https://doi.org/10.1016/j.surfcoat.2013.10.072

14. Dosdat, L.; Petitjean, J.; Vietoris, T.; Clauzeau, O. Corrosion Resistance of Different Metallic Coatings on Press-Hardened Steels for Automotive. Steel Res. Int. 2011, 82, 726-733. https://doi.org/10.1002/srin.201000291

15. Lee, M.G.; Kim, S.J.; Han, H.N.; Jeong, W.C. Application of hot press forming process to manufacture an automotive part and its finite element analysis considering phase transformation plasticity. Int. J. Mech. Sci. 2009, 51, 888-898. https://doi.org/10.1016/j.ijmecsci.2009.09.030 
16. Hayashi, K.; Nishibata, T.; Kojima, N.; Kajihara, M. Decarburization of 0.21C-1.3Mn-0.2Si Steel for Hot Stamping at Various Heating Temperatures. Solid State Phenomena 2011, 172-174, 882-892. https://doi.org/10.4028/www.scientific.net/SSP.172-174.887

17. Hamamoto, S.; Omori, H.; Asai, T,; Mizuta, N.; Jimbo, N. Yamano, T. Steel sheets for highly productive hot stamping. Kobelco Technology Review 2017, 35, 39-44.

18. Suehiro, M.; Maki, J.; Kusumi, K.; Ohgami, M.; Miyakoshi, T. Properties of Aluminum-coated Steels for Hot-forming. Nippon Steel Technical Report, 2003, 88, $295-415$.

19. Seong Guk Son, Yeonjung Hwang, Chang Wook Lee, Ji Hong Yoo, Minsu Choi Effect of Hot Stamping Heat Treatment Temperature on Resistance Spot Weldability of Al-10\% Si Coated 30MnB5 Steel Korean J. Met. Mater. 2019; 57, 778-786. https://doi.org/10.3365/KJMM.2019.57.12.778

Hidalgo, J.; Santofimia, M.J. Effect of prior austenite grain size refinement by thermal cycling on the microstructural features of as-quenched lath martensite. 2016, 47, 5288-5301. https://doi.org/10.1007/s11661-016-3525-4 